\title{
AC 2012-4328: NO SKILL LEFT BEHIND: INTELLIGENT TUTORING SYSTEMS ENABLE A NEW PARADIGM IN LEARNING
}

\author{
Mr. Hatem M. Wasfy, Advanced Science and Automation Corp.
}

Hatem Wasfy is the President of Advanced Science and Automation Corp. (ASA), a company that specializes in the development of online virtual learning environments, and advanced engineering simulations. He has helped design several interactive learning environments that include a CNC machining course, a centrifugal pump maintenance course, an undergraduate physics course, and a welding course. He received a B.S. (1994) and an M.S. (1996) in mechanical engineering from the American University in Cairo. Wasfy's research interests include advanced learning systems, cavitation modeling, computational fluid dynamics, internal combustion engine modeling and design, and AI rule-based expert systems.

\section{Dr. Tamer M. Wasfy, Indiana University-Purdue University, Indianapolis}

Tamer Wasfy received a B.S. (1989) in mechanical engineering and an M.S. (1990) in materials engineering from the American University in Cairo, and an M.Phil. (1993) and Ph.D. (1994) in mechanical engineering from Columbia University. He worked as a Research Scientist at the Department of Mechanical Engineering, Columbia University (1994-1995) and at the University of Virginia at NASA Langley Research Center (1995-1998). Wasfy is an Associate Professor at the Mechanical Engineering Department at Indiana University-Purdue University Indianapolis (IUPUI). Dr. Wasfy is also the founder and chairman of Advanced Science and Automation Corp. (founded in 1998) and AscienceTutor (founded in 2007). Wasfy's research and development areas include: flexible multibody dynamics, finite element modeling of solids and fluids, fluid-structure interaction, belt-drive dynamics, tires mechanics/dynamics, ground vehicle dynamics, visualization of numerical simulation results, engineering applications of virtual-reality and artificial intelligence. He authored and co-authored more than 70 peer-reviewed publications and gave more than 65 presentations at international conferences and invited lectures in those areas. He received two ASME best conference paper awards as first author. He is the software architect for the DIS, IVRESS, and LEA software systems, which are used by industry, government agencies, and academic institutions. Wasfy is a member of ASME, AIAA, SAE, and ASEE.

\section{Ms. Jeanne Peters, Advanced Science and Automation Corp.}

Jeanne Peters received a B.A. in math/computer science from the College of William and Mary. She worked at the NASA Langley Research Center in Hampton, Va. for more than 20 years as a Senior Programmer/Analyst for George Washington University, University of Virginia, and Old Dominion University. She co-authored more than 70 journal and conference papers in the areas of: computational mechanics, finite element method, shells/plates, composite material panels, and tires. She has also worked on numerous projects to create advanced engineering design and learning environments which include multimodal user interfaces for space systems. As Vice President of Information Technology, Peters directs the development of advanced virtual reality applications, including scientific visualization applications and web-based multimedia education/training applications.

\section{Prof. Riham M. Mahfouz, Thomas Nelson Community College}

Riham Mahfouz is the Department Head of the Chemistry Department at the Thomas Nelson Community College (TNCC), where she teaches and serves as Course Coordinator for the following courses: preparatory chemistry, organic chemistry, and online college chemistry. Mahfouz has extensive training and experience in developing online courses. She has developed online college chemistry courses using the ASSURE Model of instructional design and the standards created by the Quality Matters faculty-centered peer review process for certifying the quality of online courses. 


\title{
No Skill Left Behind: Intelligent Tutoring Systems Enable a New Paradigm in Learning
}

\begin{abstract}
In this paper, the design and merits of an automated online Intelligent Tutoring System (ITS) are presented. The ITS contains an ontology of the topics of the course topics (the course model) that guides its remedial actions when it encounters a student assessment failure. Furthermore, the ITS keeps track of the student's declarative and intuitive proficiency scores in every course topic (the student model). The ITS uses formative assessments to gauge the student's performance and to navigate the course non-linearly by finding and correcting the root cause of any assessment failure. The ITS thus ensures that the student attains the required level of proficiency in every course topic by continuously assessing and remediating these topics during course delivery. The ITS also flags terminal failures that it is unable to remediate. The proposed ITS has great potential for improving student achievement and for reducing the cost and time of learning.
\end{abstract}

\section{Introduction}

An increasing number of higher education students are receiving a significant portion of their education from online courses. According to a recent study by the Sloan Consortium, in fall $2010,31.3 \%$ of higher education students in the US, or 6.14 million students, took at least one online course ${ }^{1}$. In the above mentioned study online courses are defined as courses where $80 \%$ or more of the content is delivered online, typically with no face-to-face meetings with the course instructor. While the compound annual growth in the overall number of higher education students from fall 2002 to fall 2010 was 2.1 percent, during the same time period, the compound annual growth in the number of students taking at least one online course was $18.3 \%{ }^{1}$. This means that students who are taking online classes are becoming a larger proportion year after year of the overall population of higher education students. The same trend is taking place elsewhere around the globe and to a lesser degree in K-12 education. For example, in China, in 2006, there were 66 universities offering 8,557 online courses with a total enrollment of around 3 million students ${ }^{2}$.

According to numerous studies up to 2001, students who learn solely using high quality online resources, achieve the same level of proficiency as students who learn in a traditional classroom setting $^{3}$. A more recent study by the U.S. Department of Education's Office of Planning, Evaluation, and Policy Development ${ }^{4}$ concluded that: "classes with online learning (whether taught completely online or blended) on average produce stronger student learning outcomes than do classes with solely face-to-face instruction." This is confirmed by the findings of a survey of academic leaders that found that over two thirds believe online courses are "just as good as" or better than traditional courses ${ }^{1}$. Furthermore online instruction offers many advantages over traditional classroom instruction in terms of cost, convenience, accessibility, and lack of variability in the instruction received by the students. For these reasons, it is expected that online instruction will continue to gain ground not only in institutions of higher learning, but also in primary, middle and high schools, as well as in corporate and government training. 
Online learning however has not created a radical paradigm shift in the way students learn that takes full advantage of the capabilities of the computer. This is a typical example of technique lagging behind technology, where the question that is being asked is: "how can online learning improve the way we teach?" A more radical question however that should be asked is: "how can online learning change the way we teach?" Twigg ${ }^{5}$ likened this situation to the case of early motion pictures that were shot from a single fixed position, making them essentially stage plays on film. While this approach was an improvement over traditional plays, it did not take full advantage of the motion camera technology to change the way a story can be told, and create a radically different and much more entertaining art form.

For the most part, current online courses are developed, taught, and assessed in the same way as traditional courses. The courses are usually delivered as written online documents, pre-recorded lectures, or live lectures that mimic the traditional textbook and classroom instruction. Student performance is assessed using online quizzes and exams that mimic their traditional counterparts. Even help sessions for struggling students that fail in one or more of the course assessments are done using text, voice, or video chat that mimics traditional office hours.

\section{Comparing Cost, Learning Time and Effectiveness}

Before speaking about how technology can improve learning, we must first develop a metric or merit criterion for comparing treatments to a base case. The most logical base case is the one that is most prevalent; which is the traditional classroom setting where a teacher lectures in front of 20 to 50 students. Bloom ${ }^{6}$ defined the effect size of an intervention as follows:

Effect Size $=\frac{\text { Average }_{\text {Study }}-\text { Average }_{\text {Conventional }}}{\sigma_{\text {Conventional }}}$

where the Average $_{\text {Study }}$ is the average student score with the intervention, Average Conventional is the average student score in the traditional classroom setting, and $\sigma_{\text {Conventional }}$ is the standard deviation of the student scores in the traditional classroom setting.

Bloom $^{6}$ compared traditional classroom instruction outcomes with the outcome of a mastery level classroom where students received additional explanations and assessments, and with the outcome of one-on-one tutoring. Bloom found that the effect size of the mastery level classroom was $+1 \sigma$, and the effect size of one-on-one tutoring was $+2 \sigma$. The term "2-Sigma challenge" refers to the goal of finding a learning technique that would match the effect size of one-on-one tutoring. Yet Bloom's effect size does not take into account a crucial factor; the cost of the intervention as compared to the cost of classroom instruction. Since the traditional classroom in Bloom's study contained 30 students, we would expect the cost of hiring 30 tutors to teach each student individually to be about 30 times larger than the cost of teaching the traditional class. We can thus define the cost ratio of the intervention as:

$$
\text { Cost Ratio }=\frac{\text { Cost }_{\text {Study }}}{\text { Cost }_{\text {Conventional }}}
$$


Thus a more meaningful criterion for comparing interventions that takes into account both effectiveness and cost can be defined as the net effect per cost ratio, where:

Net Effect per Cost Ratio $=$ Net Effect $/$ Cost Ratio $=(1+$ Effect Size $) /$ Cost Ratio

This criterion assumes that the cost has the same importance as the net effect. The learning time in Bloom's study was held constant in each case. Assuming time to be of the same importance as cost and effect size, a further refinement of the merit criterion is to include in it the time ratio, where:

Time Ratio $=\frac{\text { Time }_{\text {Study }}}{\text { Time }_{\text {Conventional }}}$

In meta-analysis study of 32 computer-based courses, the time ratio when taking conventional classroom learning as the base case was found to be about two thirds ${ }^{7}$. The final merit criterion of a given intervention as compared to traditional instruction is defined as:

\section{Merit Criterion $=(1+$ Effect Size $) /($ Cost Ratio $\times$ Time Ratio $)$}

The merit criterion of the base case is always equal to one. For Bloom's study, the merit criterion for the one-on-one tutoring case is equal to 0.1 , given an effect size of 2 , a cost ratio of 10 and a time ratio of 1 . Based on this criterion, interventions with a score that is larger than one are better overall in terms of cost, amount of time spent by the students and effectiveness than the base case.

\section{Identifying the Strength of Tutoring}

In order to produce a radical improvement in learning, one must start with the most effective form of traditional teaching, then attempt to improve over it. In terms of learning effectiveness, the one-on-one tutoring case, as was shown by Bloom, is a big improvement over traditional classroom instruction. The next step is to try to identify the elements that make this form of teaching effective, so they can be incorporated into future computerized learning systems:

1. Remains within the student's attention span: A good tutor presents the information in portions that can be easily digested by the student. Thus the tutor should divide his lesson into manageable logical topic sections that do not exceed in duration of delivery the attention span of the student. A number of studies have concluded that the attention span of students becomes shorter as a lecture progresses, dropping to between 3 to 4 minutes towards the end of a standard lecture ${ }^{8}$.

2. Formative assessments: Formative assessment (sometimes called AfL or assessment for learning) involves "weaving" the assessment into the fabric of the course and providing timely feedback on student performance to help students improve". This is in contrast to the summative assessments that are used in traditional courses, and that take the form of tests and quizzes. In summative assessment, the assessment takes place at the end of a long learning process and does not generally affect the learning process. The results of the formative assessments, on the other hand, are used to provide real time instructional adjustments such as 
going over a course section again, or offering more practice opportunities ${ }^{10,11}$. A good tutor constantly assesses the student's understanding while administering the learning. This ensures that any problem the student has in understanding the content is addressed right away. The results of the formative assessments alter the learning process, where the tutor can go over a section of material again if the student did not understand it correctly the first time. The tutor can also skip a section if the student is already proficient in its content to save time. The AfL approach was found to improve student achievement in studies of computer based ${ }^{9}$ and classroom based $^{12}$ learning.

3. Identifying the cause of failure and remediating it: A good tutor is able to quickly identify the cause of a student failure in the assessment of a given topic. This cause might not be related to the current topic that is being assessed; rather it might be related to deficiency in the student's understanding of a previous "upstream" topic that the current topic depends on.

4. Identifying the type of failure and remediating it: When a student fails to answer an assessment question correctly in the allotted time, the failure is generally due to one of two reasons: a deficiency in the student's declarative knowledge or a deficiency in the student's intuitive knowledge. Declarative knowledge measures the correctness of the student responses, while intuitive knowledge focuses on the speed with which students can arrive at these correct responses ${ }^{13}$. The reason why the two types of knowledge need to be distinguished is because the remedial action that needs to be performed in case of a deficiency is different for either type of knowledge. In case of a deficiency in declarative knowledge, the student needs to receive additional or repeated instruction since he/she does not grasp the concept correctly. A deficiency in intuitive knowledge, on the other hand, means that the student understands the concept and is answering correctly, but needs to go over more exercise questions to be able to solve the assessment questions more quickly and intuitively.

5. Uses interactive demonstrations: A good tutor does not just lecture to the student, but also uses interactive demonstrations that the student can use for hands on learning. This is especially important for relating the concepts that are being taught to the real world in fields such as physics, chemistry, mechanics, ...

6. Individualized learning: A good tutor tailors the delivery method, sequence and pace to the needs of the student. This element was identified as a key to innovation in distance learning by experts in online learning 5 .

7. Large breadth of knowledge: A good tutor can remediate problems related to the student's knowledge that affect the learning even if these problems are related to a different course than the one that is being studied. For example, a good chemistry tutor is able and willing to remediate problems caused by deficiencies in the student's understanding of certain mathematical concepts.

8. Ensuring proficiency in every topic: A good tutor makes sure that the student has achieved the required level of proficiency in each course topic before moving on to the next topic.

9. Uses scaffolding to guide students to the correct answer: A good tutor does not just hand the student the correct answer when the student makes a mistake. The tutor should rather try to guide the student towards the correct answer by steering the student in the right direction.

It is clear that not all tutors use the above mentioned elements effectively in their tutoring. This is probably the main reason why the effect size of one-on-one tutoring can vary greatly from one study to another. In Bloom's study, the effect size of one-on-one tutoring was equal to 2 for what Bloom described as "good" tutors. In a meta-study of 52 studies where tutoring was used either 
as a supplement to or a replacement of conventional teaching ${ }^{14}$, the effect size for one-on-one tutoring ranged from 0 to 2.3 with an average of 0.4 . The component studies of this meta-study involved peer (student), and paraprofessional tutors, rather than professional tutors. It is also interesting to note that the average effect size in this meta-study for one-on-one tutoring involving mathematics was 0.6 for 18 studies, or more than twice the average effect size of 0.29 that was calculated from 30 studies involving reading.

\section{Design of an Effective Automated Online Course}

Many of the current online, or distance learning, courses are facilitated by an instructor who answers student questions, grades homework and exams, and even sometimes lectures to students using online video or audio conferencing. Yet an increasing number of online courses have incorporated greater course automation, especially in the areas of lecture delivery, and homework and exam grading. Online courses can be classified based on the degree of automation of the course delivery, which is inversely proportional to the degree of involvement of a human instructor in the learning activities. Three online course classifications can be used

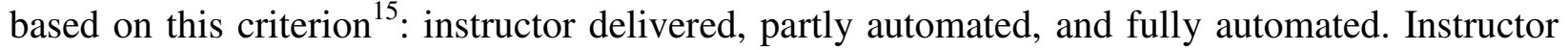
delivered online courses are defined as courses where $30 \%$ or less of the course activities are automated. From $30 \%$ to $79 \%$ of the course activities in partly automated online courses are automated. This usually includes some of the lecture delivery and some or all of the homework grading. Courses in which more than $80 \%$ of the course activities are automated fall into the fully automated category. Typically with higher degrees of course automation, the course can be delivered with little or no involvement from an instructor.

A small study of a fully automated undergraduate machining course suggests that in terms of student comprehension, using only a well designed fully automated online course is as effective as traditional classroom/textbook/lab instruction ${ }^{16}$. In this study, the mean score for students who learned the lecture material in a traditional classroom setting was $88.3 \%$ with a standard deviation of $9.0 \%$, while the mean score for students who learned solely using the fully automated online course was $90.0 \%$ with a standard deviation of $10.5 \%$. Even though the effect size for this course was effectively zero, the merit criterion for this and similar courses as defined above is substantial. This is based on the fact that similar courses could be made available for about the price of a typical textbook, or about $\$ 100$. Assuming the student takes 10 such courses per year, this would constitute an overall cost of $\$ 1,000$ per year. The national average for the yearly per student expenses for tuition, fees, books and supplies at a two year college was $\$ 4,145$ in $2011^{17}$. If we factor in a time ratio of two thirds, this would result in a merit criterion for a curriculum of similar fully automated online courses of 6.22. This merit criterion would be even larger if the cost is compared to that of a four year public university that costs an average of $\$ 9,412$ for in-state tuition, fees, books and supplies in $2011^{17}$. One could also validly argue that using fully automated online courses would significantly reduce the student's housing and transportation expenditures, since the student will not need to move to more expensive oncampus housing, or commute to school.

In order to be most effective, a fully automated online course should incorporate the elements of strength that are related to one-on-one tutoring that were indentified above. The course should be divided into short segments that do not exceed in duration the shortest attention span that 
students have at the end of a typical lecture. That shortest attention span was found to be in the range of 3 to 4 minutes $^{8}$. Yet students who use computer based learning can sit in front of the computer for much longer than the duration of a typical lecture. Thus it is recommended that the course segments should be even shorter; in the range of 1 to 2 minutes. This will also allow for easy course navigation; where students can quickly find and access the exact piece of information they need. These short segments that constitute the smallest significant and independent elements of the course can be referred to as Knowledge Objects (KOs) ${ }^{18,19}$ or as Sharable Content Objects (SCO) that are described by the SCORM (Sharable Content Object Reference Model) standard as representing: "The lowest level of granularity of a learning resource that is tracked by an LMS" ${ }^{20}$. KOs should be designed to be as much as possible independent of their learning context. This allows KOs to be reused in different online courses which minimizes development costs.

In order to be able to track the source of failure in any of the course's assessments, the relationships between the KOs should be identified and programmed into an overall ontology of the course topics. A single KO or a group of KOs that cover a single topic form an ontology node. The relationship between ontology nodes should be identified and weighed in terms of percent dependency, where the sum of the percent dependencies of any ontology node on its upstream nodes should add up to $100 \%$. The dependency scores of each ontology node in relation to its upstream nodes are programmed into the ontology by the course designer. The entire course is constructed from these KOs arranged internally as an ontology of interdependent course nodes. Students however view the KOs as an ordered hierarchical tree of course topics (Figure 1). The ontology of course nodes can be referred to as the course model.

The navigation of most online courses is done linearly; typically by pressing the next button to go to the next course section. An effective automated course delivery system however, should guide the student through the course using an Intelligent Tutoring System (ITS). In ITS navigation, it is the computer that determines which topic the student needs to see next. The ITS's navigation decisions are mainly based on the results of continuous formative assessments that are integrated in each course ontology node. Hence while in linear navigation all students experience the course in the same way, in ITS course navigation, each student experiences the course differently. For example with ITS navigation, some students might be taken to previous sections that they need to review because of a deficiency in their declarative knowledge, some students might be shown more solved exercise problems based on a deficiency in their intuitive knowledge, and some students might be allowed to skip over one or more sections if the system determines they already know the content based on a pre assessment. Thus ITS navigation provides a form of individualized learning.

If it does not encounter an assessment failure, the ITS navigates the course linearly going from one $\mathrm{KO}$ to the next $\mathrm{KO}$ on the course's hierarchical tree outline. After the ITS finishes a given ontology node, it presents the student with an assessment of their declarative and intuitive knowledge. During course delivery, students that fail to answer the assessment questions correctly receive a remedial action in the form of real-time feedback on the mistakes that they made, and additional or repeated instruction to remediate their declarative knowledge. Students that answer questions correctly but exceed the questions' time receive remedial action in the 
form of additional solved and unsolved exercise questions to remediate their intuitive knowledge.

The ITS navigates the course using an approach we call Intelligent Formative Assessment (IFA) that is summarized by the decision tree in Figure 2. If pre assessment is enabled for a given ontology node, the student is asked before going over the node if he/she wishes to go over the current topic or if he/she wishes to be immediately pre assessed in order to have a chance to skip over the current topic. If the student agrees to be pre assessed and he/she passes the pre assessment, the student is allowed to skip over the current topic and move on to the next one. If, on the other hand, the student declines to take or fails the pre assessment, then the IE goes over the content of the current node. After going over the node's content, the ITS presents the student with a post assessment. If the student passes the post assessment, he/she is taken to the next ontology node. If however the student fails the post assessment, then the student is given a choice to go over the current node again. If the student declines to go over the current node again, then he/she is shown a list of the current node's upstream nodes and asked if he/she wishes to go to any of the upstream nodes. If the student answers in the affirmative, the selected upstream node is covered again, re-assessed, and the student is then taken back to the current node. If the student answers in the negative, then the system automatically assesses the upstream nodes one by one starting with the one that has most likely caused the failure. The decision of which node to assess first is based on the percent dependency scores of the upstream nodes. If an assessment failure occurs in any of the upstream nodes, then the ITS takes the student back to the failed upstream node, reassesses that node, and then goes back to the current node. If, on the other hand, all the upstream nodes pass assessment, then the student is again given the choice to go over the failed node's content. If the student declines to go over the failed node's content again, then this signals a terminal failure in the failed node. A terminal failure is defined as a failure that cannot be remediated by going over the knowledge in the node again or in more detail, and that is not related to a lack of understanding of an upstream node. The ITS then directs the student to other course nodes that are not downstream of the terminally failed node.

The course professor is alerted of any terminal failures in order to take corrective action by going over the material of the failed node with the student that experienced the terminal failure, or by redesigning or adding more explanation to the node to improve student comprehension of its topic. The number of regular and terminal failures related to each ontology node for all the students taking the course is tracked. This information is used to help improve the course by identifying problematic nodes that students are having difficulties with. The intelligence aspect in current ITSs focuses mainly on guiding the student to the correct answer of assessment questions rather than trying to find the root source of deficiency in the student's knowledge that is causing the failure ${ }^{21}$. The IFA approach will ensure that the root cause of a student's failure is found and corrected, rather than only treating the symptom by guiding the student to the right answer. Since the IFA process described above is recursive, the root cause of the failure can be traced up the ontology tree several levels beyond the nodes immediately upstream of the failed node. In case the course ontology is tied in to the ontologies of other courses in an overall curriculum ontology, the ITS's remedial actions can cross course boundaries into adjacent courses and disciplines. 
Traditional education usually assesses the average proficiency of students over an entire course using summative assessment, not their actual proficiency in every course topic. Hence even a student who finishes a course with an A grade might have a failing proficiency level in one or more critical course topics. Furthermore, during the course, struggling students are not given enough chance to improve their performance due to the limited amount of time during which the course is offered, limitations on their access to the course instructor, and not being offered timely remedial learning when a failure is encountered. Due to this lack of knowledge about the student's actual proficiency level in the component topics of the course he/she has passed, companies often find it necessary to retrain incoming workers in much of the knowledge that they need on the job, despite the fact that the workers should have already learned this knowledge in school.

Each student's declarative, and intuitive knowledge scores for each finished ontology node is stored in his/her student model. The student model thus provides an effective way of tracking the student's progress through the course or through an entire curriculum. In this case, the student model can replace the traditional transcript in the role of tracking student progress in every curriculum topic. Lifelong learning beyond the school year can still be tracked using the student model which can be transferred from one learning institution to another or to employers. We call this approach that ensures that students achieve the required level of proficiency in every curriculum topic in a verifiable way the "no skill left behind" approach.

\section{Conclusion}

Even though one-on-one tutoring has been shown to greatly improve learning outcomes, it is too expensive to implement on a large scale. By using advanced Intelligent Tutoring Systems (ITSs), it is possible to match or even exceed the effect size of one-on-one tutoring at a fraction of the cost and time commitment that is required by traditional classroom instruction. By dividing the course into interconnected ontology nodes, using formative assessment for each node, and tracking the cause of any failure up the ontology tree, the ITS can ensure that the students achieve the required proficiency level in every course component topic.

\section{References}

1. Allen, E., and Seaman, J. Going the Distance: Online Education in the United States, 2011. The Sloan Consortium, November 2011. See also URL http://sloanconsortium.org

2. Zhao, Y., Zhang, G., and Li, N. "The Life of Internet Colleges: Policies, Problems, and Prospects of Higher Education in China”, EDUCAUSE Review, 41(6), pp. 48-59, Nov/Dec 2006.

3. Russell, T. The No Significant Difference Phenomenon: A Comparative Research Annotated Bibliography on Technology for Distance Education, $5^{\text {th }}$ Edition. IDECC, Montgomery, AL, 2001. See also URL http://www.nosignificantdifference.org/

4. Means, B., Toyama, Y., Murphy, R., Bakia, M., and Jones, K. Evaluation of Evidence-Based Practices in Online Learning: A Meta-Analysis and Review of Online Learning Studies. U.S. Department of Education: Office of Planning, Evaluation, and Policy Development. September 2010. See also URL http://www2.ed.gov/rschstat/eval/tech/evidence-based-practices/finalreport.pdf

5. Twigg, C.A. Innovation in Online Learning: Moving Beyond No Significant Difference. The Pew Learning and Technology Program, 2001. 
6. Bloom, B.S. "The 2 Sigma Problem: The Search for Methods of Group Instruction as Effective as One-on-One Tutoring." Educational Researcher, 13(6), pp. 4-16, 1984.

7. Kulik, C.C., and Kulik, J.A. "Effectiveness of computer-based instruction: An updated analysis." Computers in Human Behavior, 7, pp. 75-94, 1991.

8. Middendorf, J., and Kalish, A. "The "change-up" in lectures." The National Teaching and Learning Forum, 5(2), pp. 1-5, 1996.

9. Shute, V.J., Hansen, E., and Almond, R. "You Can't Fatten a Hog by Weighing it - Or Can You? Evaluating an Assessment for Learning System Called ACED." International Journal of Artificial Intelligence in Education. 18(4), 2008.

10. Shute, V.J., Ventura, M., Bauer, M., and Zapata-Rivera, D. "Melding the power of serious games and embedded assessment to monitor and foster learning: Flow and grow." In U. Ritterfeld, M. Cody, and P. Vorderer (Eds.), Serious Games: Mechanisms and Effects. Philadelphia, PA: Routledge. pp. 295-321, 2009.

11. Black, P., and Wiliam, D. "Inside the black box: Raising standards through classroom assessment." Phi Delta Kappan, 80(2), pp. 139-148, 1998.

12. Black, P., and Wiliam, D. "Assessment and classroom learning." Assessment in Education: Principles, Policy \& Practice. 5(1), pp. 7-71, 1998.

13. Swaak, J., de Jong, T., and van Joolingen, W. "The Effect of Discovery Learning and Expository Instruction on the acquisition of Definitional and Intuitive Knowledge." Journal of Computer Assisted Learning, 20, pp. 225234, May 2004.

14. Cohen, P.A., Kulik, J.A., and Kulik, C.C. "Educational outcomes of tutoring: A meta-analysis of findings." American Educational Research Journal. 19, pp. 237-248, 1984.

15. Wasfy, H.M., Wasfy, T.M., Peters, J.M. and Mahfouz, R.M., "Virtual Reality Enhanced Online Learning Environments as a Substitute for Classroom Instruction." ASME DETC2011-48826, Proceedings of the ASME 2011 International Design Engineering Technical Conferences \& Computers and Information in Engineering Conference (IDETC/CIE 2011), Washington D.C., August 2011.

16. Fernandez, E., Workman-German, J., El-Mounayri, H., and Padalia, C. "Assessment of the Pedagogical Value of an Innovative E-Learning Environment That Uses Virtual Reality”, 2008 ASEE IL/IN conference at RoseHulman Institute of Technology, April 3-5, 2008.

17. Trends in College Pricing 2011. The College Board, 2011. See also URL http:// www.collegeboard.org

18. Wasfy, A.M., Wasfy, T.M., El-Mounayri, H., and Aw, D., "Web-based multimedia lecture delivery system with text-to-speech and virtual instructors," ASME DETC2005-84692, 25 ${ }^{\text {th }}$ Computers and Information in Engineering (CIE) Conference, Long Beach, CA, September 2005.

19. Wasfy, T.M., "LEA: advanced environment for multimedia and virtual-reality web-based education and training," DETC2006-99292, $26^{\text {th }}$ Computers and Information in Engineering (CIE) Conference, ASME DETC, Philadelphia, PA, September 2006.

20. Sharable Content Object Reference Model (SCORM), $2^{\text {nd }}$ Edition, 2004. See also URL http:// www.adlnet.org

21. VanLehn, K., Lynch, C., Schulze, K., Shapiro, J.A., Shelby, R., Taylor, L., Treacy, D., Einstein, A., and Wintersgill, M. "The Andes Physics Tutoring System: Lessons Learned." International Journal of Artificial Intelligence in Education, 15(3), pp. 147-204, 2005. 


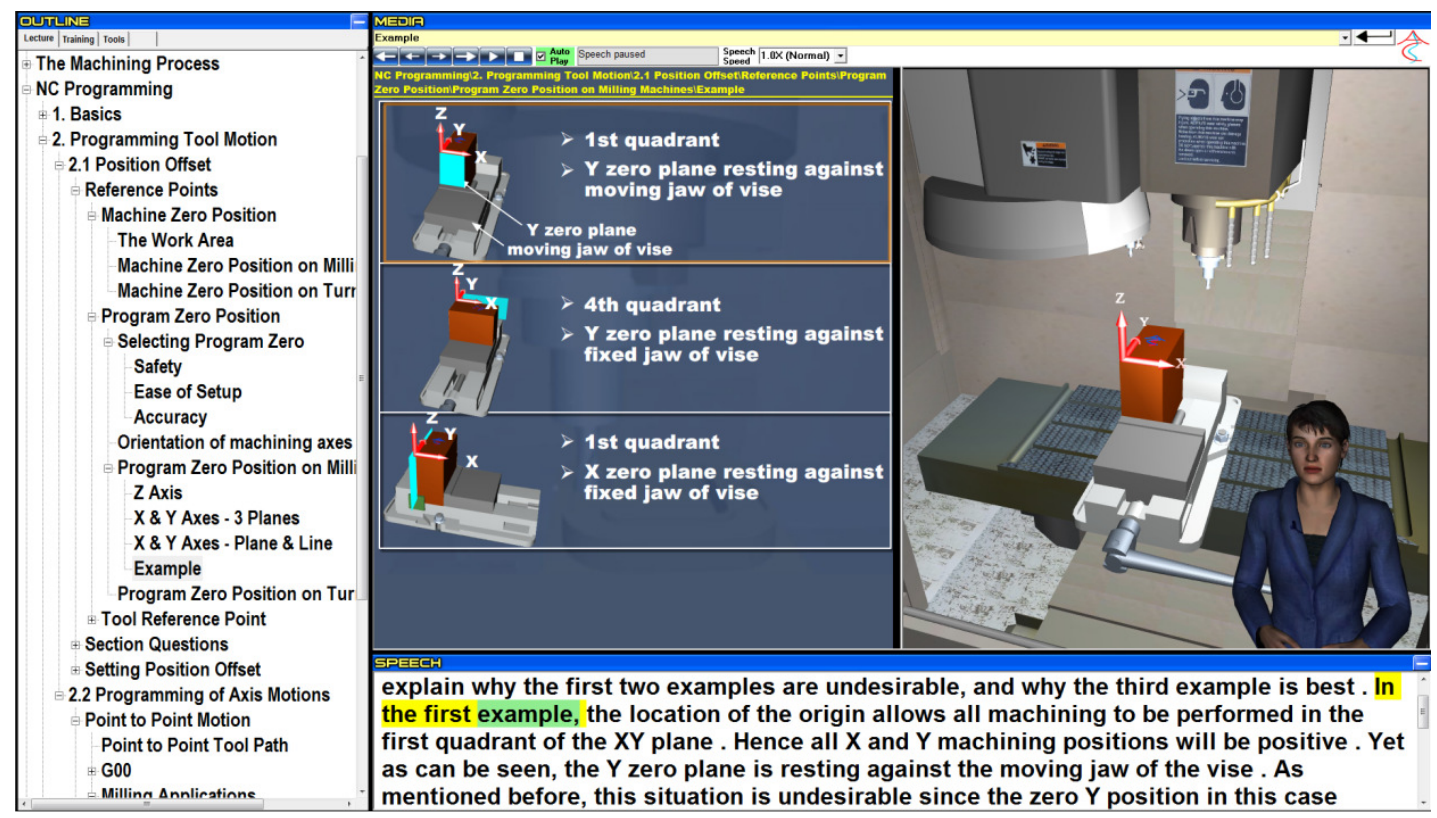

Figure 1. Knowledge object from a fully automated manufacturing course. The virtual reality window on the right contains the virtual instructor and interactive lab. The lecture window in the center is running an Adobe Flash animated slide. The speech window at the bottom contains a text version of the virtual tutor's computer generated speech. The outline window on the left contains a hierarchical clickable tree of the lecture's knowledge objects.

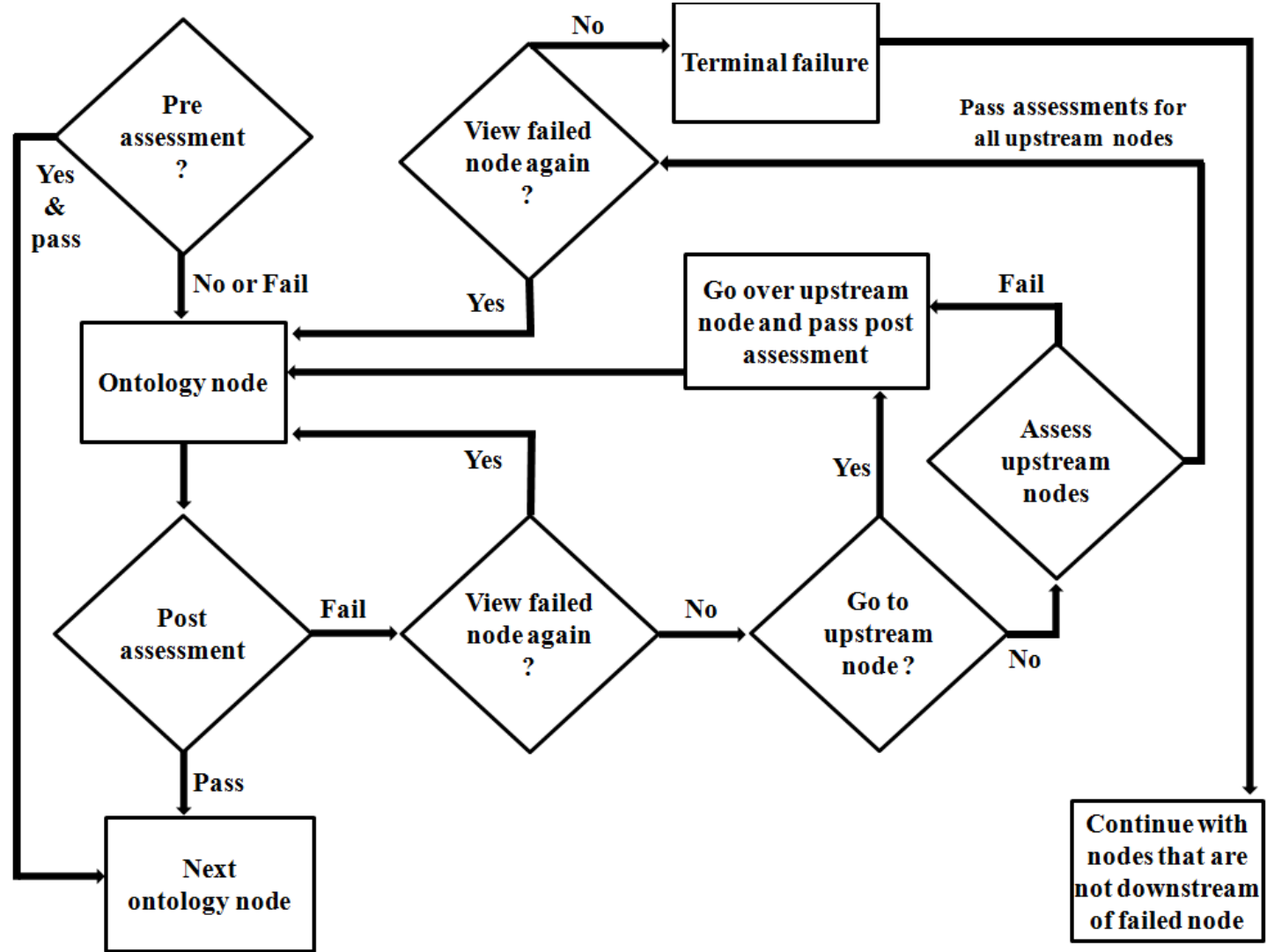

Figure 2. Decision tree for ITS navigation using Intelligent Formative Assessment. 